\title{
Confirmatory Factor Analysis of Aurora-a Battery on Children
}

\author{
Sara Aghababaei ${ }^{1}$, Mokhtar Malekpour ${ }^{2}$, Mohammad Bagher Kajbaf $^{1} \&$ Ahmad Abedi ${ }^{2}$ \\ ${ }^{1}$ Department of Psychology, University of Isfahan, Isfahan, Iran \\ ${ }^{2}$ Departments of Children with Special Needs, University of Isfahan, Isfahan, Iran \\ Correspondence: Mokhtar Malekpour, Department of Children with Special Needs, University of Isfahan, \\ Isfahan, Iran. Address: Isfahan, Azadi Sq., University of Isfahan, Department of Children with Special Needs, \\ Faculty of Psychology and Educational Sciences. E-mail: MokhtarMalekpour@ymail.com
}

Received: February 27, 2016

Accepted: March 24, 2016

Online Published: July 4, 2016

doi:10.5539/mas.v10n10p99

URL: http://dx.doi.org/10.5539/mas.v10n10p99

\begin{abstract}
The aim of this research is confirmatory factor analysis of Aurora-a Battery on Iranian children. Aurora-a Battery is a cognitive assessment according to Robert J. Sternberg's theory of Successful Intelligence. 400 children 9-12 years old were selected through multi-steps sampling method and were tested with Aurora-a test. These children were from geographically diverse schools in Isfahan city, Iran. The factor analysis of data was performed through Amos software. Fit indices show that data fit with model. Moreover, the correlation between test total score and the analytical, creative and practical intelligences were $0.91,0.94$ and 0.84 , respectively. Alpha for Aurora's total score was equal to 0.92 as well. Aurora-a test can be an appropriate and valid instrument for identification gifted children aged 9-12 according to Sternberg's theory of successful intelligence. This test allows many children to be identified as gifted which in turn provides the opportunity of further development of their potential.
\end{abstract}

Keywords: Aurora-A Battery, confirmatory factor analysis, children

\section{Introduction}

Like his predecessors, Robert Sternberg was concerned with the narrow nature of intelligence that is measured by conventional IQ tests. "Successful intelligence" as defined by Sternberg $(1985 ; 1997)$ is the ability to succeed in life and particularly at the goals you have set for yourself with in your environmental context. The determination of whether one is "successfully intelligent "is according to the extent to which the person is effective in adapting to, shaping, and selecting environments that allow for maximal achievement (Sternberg, 2002).

Sternberg's theory of successful intelligence indicates that the contribution of three types of abilities which are selected and balanced as required is equal in successful achievement of goals. These abilities are analytical ability, creative ability, and practical ability (Sternberg, 1999; 2005).

Analytical ability is used in analyzing, evaluating, judging, and comparing and contrasting. Analytic abilities are shown in reasoning and logical thinking. They are exercised in activities such as persuasive writing ,debating, research, and mathematical problem-solving. Creative abilities can be seen in designing and creating new ideas in activities such as writing, painting and building. Practical ability is involved when people use their abilities to solve daily problems at job or at home (Mandelman, Kornilov, Sternberg, \& Grigorenko, 2010).

Conventional tests of intelligence have more focus on analytical abilities and partly ignore the practical and creative abilities (Sternberg, 2015). Such tests predict a large variety of performances (Herrnstein \& Murray, 1994; Jensen, 1998; Schmidt \& Hunter, 1998), but perhaps not at the highest level that can be achieved (Sternberg, 2010). Base on this idea of intelligence, analytical, creative, and practical abilities are relatively independent of each other and play important role in mental functioning and success in life (Kornilov, Tan, Elliott, Sternberg, \& Grigorenko, 2012).

Recently, Carroll's model and the Horn-Cattell model have been combined into the Cattell-Horn-Carroll (CHC) theory (Flanagan \& Harrison, 2005). Although the CHC model still incorporates a $\mathrm{g}$ factor, its main emphasis is on the measurement of middle-stratum factors. This model is affected new versions of intelligence tests, consisted of the fifth edition of the Stanford-Binet (Roid \& Barram, 2004), the second edition of the Kaufman 
Assessment Battery for Children (KABC-II; Kaufman, Lichtenberger, Fletcher-Janzen, \& Kaufman, 2005), and the third edition of the Woodcock-Johnson Cognitive Abilities Assessment (WJ-III; Mather, Wendling, \& Woodcock, 2001).

It is justifiable to state that recently new developments have been emerged in identification models (for example, Joseph Renzulli, Howard Gardner, and others) that have been used methods in identifying gifted children beyond traditional test (Sternberg, 2010).

Renzulli's (2005) views giftedness as the interaction of three characteristics: task commitment, well-above average ability, and creativity. Gardner's theory of multiple intelligences (1993; 1999), (including of interpersonal, intrapersonal, spatial, naturalistic, language, logical-mathematical, bodily-kinesthetic, and musical) consists a wide range of abilities that would require differing amounts of creativity. But the tests used to measure IQ have not changed much (Sternberg, 2010). These tests still measure the very basic construct of "general ability" that spearman specified in the twentieth century (Sternberg, 2015). According to Sternberg (2010) our efforts have been emphasized toward developing new types of intelligence tests in broader ways than has been used in the past.

The Aurora battery is according to Sternberg's theory of successful intelligence. Aurora tries to assess kinds of cognitive abilities, looking at strengths in verbal, visual-spatial and numerical content domains within each group of ability and across abilities as well. It is designed to emphasize the identification and development of gifted children between the ages of 9 and 12 years. Aurora was planned to assess abilities that may result in advantage not only within but also beyond the range of the system of schooling - in the everyday life and in the long term, even after the school years are over. Therefore Aurora has the potential to recognize students who are missed when only traditional methods are applied to assess gifted children (Chart, Grigorenko, \& Sternberg, 2008).

The nature of the Aurora Battery is to provide child's assessments in different aspects of intellectual abilities (Chart et al., 2008).

The aim of this study is to test the 3-Factor model according to Sternberg's theory of successful intelligence through Aurora Test on Iranian children.

\section{Method}

\subsection{Subjects}

The samples consisted of 400 Iranian students (200 boy and 200 girl) 9-12 years old. Three age groups including 9-10 (133 students), 10-11 (133 students), and 11-12 (134 students) are considered. These samples came from all social-economical areas of Isfahan, Iran.

Multi-steps sampling method was employed. Three areas were randomly selected from six educational areas in Isfahan. Then, 24 schools were randomly selected. All 400 students were randomly selected from these 24 schools.

\subsection{Materials}

The Aurora test used in this study was described in this section.

Aurora-a: Aurora-A is a paper and pencil test that assesses analytical, creative, and practical abilities in children aged 9-12. It includes of 16 subtests: five analytical, five creative, and six practical. The test is determined by change in its kinds of item formats (multiple choice; short answer; and open-ended items). The subtests were planned to assess abilities across and between stimulus domains (six verbal-words, five numerical-numbers, and six figural-Images subtests) and item formats such that a balanced range of opportunities could be offered to demonstrate different abilities within and across domains (Chart et al., 2008; Tan et al., 2009).

Table 1 shows Aurora subtests and item response format. 
Table 1. Aurora-a battery subtests

\begin{tabular}{|c|c|c|c|}
\hline & Analytical & Creative & Practical \\
\hline Images & $\begin{array}{l}\text { 1. Floating Boats: } \\
(10 \text { items })(\mathrm{MC})\end{array}$ & $\begin{array}{l}\text { 6. Book Covers: } \\
\text { (5 items) (OE) } \\
\text { 7. Multiple Uses: } \\
\text { (5 items) (OE) }\end{array}$ & $\begin{array}{l}\text { 11. Paper Cutting: } \\
\text { (10 items) (MC) } \\
\text { 12. Toy Shadows: } \\
\text { ( } 8 \text { items) }(\mathrm{MC})\end{array}$ \\
\hline Words & $\begin{array}{l}\text { 2. Words That Sound the Same (Homophone } \\
\qquad \begin{array}{l}\text { Blanks): } \\
\text { (14 items) (RW) } \\
\text { 3. Metaphors: } \\
\text { (9 items) (OE) }\end{array}\end{array}$ & $\begin{array}{l}\text { 8. Conversations: } \\
\text { (10 items) (OE) } \\
\text { 9.Interesting Language: } \\
\text { (10 items) }(\mathrm{MC})\end{array}$ & $\begin{array}{l}\text { 13. Headlines: } \\
\text { (14items) (RW) } \\
\text { 14. Decisions: } \\
\text { (3 items) (RW) }\end{array}$ \\
\hline Numbers & $\begin{array}{l}\text { 4. Number Cards } \\
\text { (Letter Math) : } \\
\text { (5 items) (RW) } \\
\text { 5. Story Problems } \\
\text { (Algebra): } \\
\text { (7 items) (RW) }\end{array}$ & $\begin{array}{l}\text { 10. Number Talk: } \\
\text { (7 items) (OE) }\end{array}$ & $\begin{array}{l}\text { 15. Maps (Logistics } \\
\text { Mapping): } \\
\text { (10 items) (RW) } \\
\text { 16. Money: } \\
\text { (5 items) (RW) }\end{array}$ \\
\hline
\end{tabular}

Note. MC: Multiple Choices. OE: Open-ended items. RW: Answers are either Right or Wrong.

\subsection{Procedure}

In order to adapt and standardize Aurora test, first, this test was translated to Farsi. Afterward, some of the items in the test were altered in order to be properly understood within the Iranian culture. This was done in consultation with experts of linguistics and English literature, specialists in the field of gifted children and the makers of the test. The initial pilot version of this adapted test was administered to 50 children and the final version of the test was obtained after resolving problems revealed in the pilot administration. Also at each meeting of administration of Aurora test, a combination of open-ended, multiple choice, and right or wrong subsets were presented to the children.

\subsection{Aurora Administration}

Aurora-A was administered to all age groups in multiple sessions, one session per day. Data from groups were gathered in three sessions of $1 \mathrm{hr}$. each. The three sessions were on consecutive days. The test was divided into 3 packets (each packets included 5-6 subtests in one session). This pattern was used for all schools.

\section{Data Analysis}

The data were analyzed using the SPSS and Amos statistical package and using the descriptive statistics, reliability and validity.

\section{Results}

Table 2 shows descriptive statistics for each of the subtests. Table 3 shows correlations between the subtests and the total score of the Aurora-a test. Moreover, the correlations between analytical, creative and practical abilities and Aurora test's total score were 0.91, 0.94 and 0.84, respectively. Furthermore, the correlations between the subtests of the Aurora-a and the total score are shown in Table 3.

\subsection{Reliability}

Overall internal consistency is calculated using Cronbach's Alpha Coefficient, to evaluate Aurora's total score reliability. Since $\alpha$ is equal to 0.92 for Aurora's total score, it is statistically reliable. For analytical, creative and practical intelligence, $\alpha$ is equal to $0.83,0.88$ and 0.70 , respectively. 
Table 2. Descriptive statistics of domains by samples in Aurora test

\begin{tabular}{|c|c|c|c|}
\hline \multirow{2}{*}{$\frac{\text { Ability }}{\text { Analytical abilitie }}$} & \multicolumn{3}{|c|}{$\mathrm{N}$ MinimumMaximumMean SD } \\
\hline & \multirow[b]{2}{*}{2} & \multirow[b]{2}{*}{53} & \multirow[b]{2}{*}{25.9210 .61} \\
\hline Analytical- word 400 & & & \\
\hline Analytical- number 400 & 00 & 12 & 5.012 .38 \\
\hline Analytical- image 400 & 0 & 10 & $5.67 \quad 2.24$ \\
\hline \multicolumn{4}{|l|}{ Creative abilities } \\
\hline Creative- word 400 & 6 & 63 & 39.1010 .83 \\
\hline Creative- number 400 & 2 & 38 & 16.176 .29 \\
\hline Creative- image 400 & 8 & 52 & 32.598 .10 \\
\hline \multicolumn{4}{|l|}{ Practical- abilities } \\
\hline Practical-word 400 & 0.36 & 27 & 14.505 .74 \\
\hline Practical-number 400 & 3.50 & 25 & 16.884 .03 \\
\hline Practical-image 400 & 2 & 18 & 9.463 .19 \\
\hline
\end{tabular}

Table 3. Subtests- total correlations

\begin{tabular}{llll}
\cline { 2 - 3 } subtests & A & Total \\
\cline { 2 - 4 } AW & 0.97 & 0.85 \\
AI & 0.62 & 0.63 \\
AN & 0.77 & 0.78 \\
& C & \\
CW & 0.91 & 0.86 \\
CI & 0.87 & 0.81 \\
CN & 0.80 & 0.75 \\
& p & \\
PW & 0.89 & 0.79 \\
PI & 0.77 & 0.60 \\
PN & 0.82 & 0.68 \\
\hline
\end{tabular}

Note. All coefficients are significant at $\mathrm{p}<.001$.

$\mathrm{A}=$ Analytical

$\mathrm{AW}=$ Analytical Word

$\mathrm{AI}=$ Analytical Image

AN $=$ Analytical Number

$$
\mathrm{P}=\text { Practical }
$$

$$
\mathrm{PW}=\text { Practical Word }
$$$$
\text { PI = Practical Image }
$$$$
\mathrm{PN}=\text { Practical Number }
$$

$$
\begin{gathered}
\mathrm{C}=\text { Creative } \\
\mathrm{CW}=\text { Creative Word } \\
\mathrm{CI}=\text { Creative Image } \\
\mathrm{CN}=\text { Creative Number }
\end{gathered}
$$

\subsection{Confirmatory Factor Analysis (CFA)}

The model included three first-order ability factors (analytical intelligence included 5 subtests, creative included 5 subtests and practical intelligence included 6 subtests). 


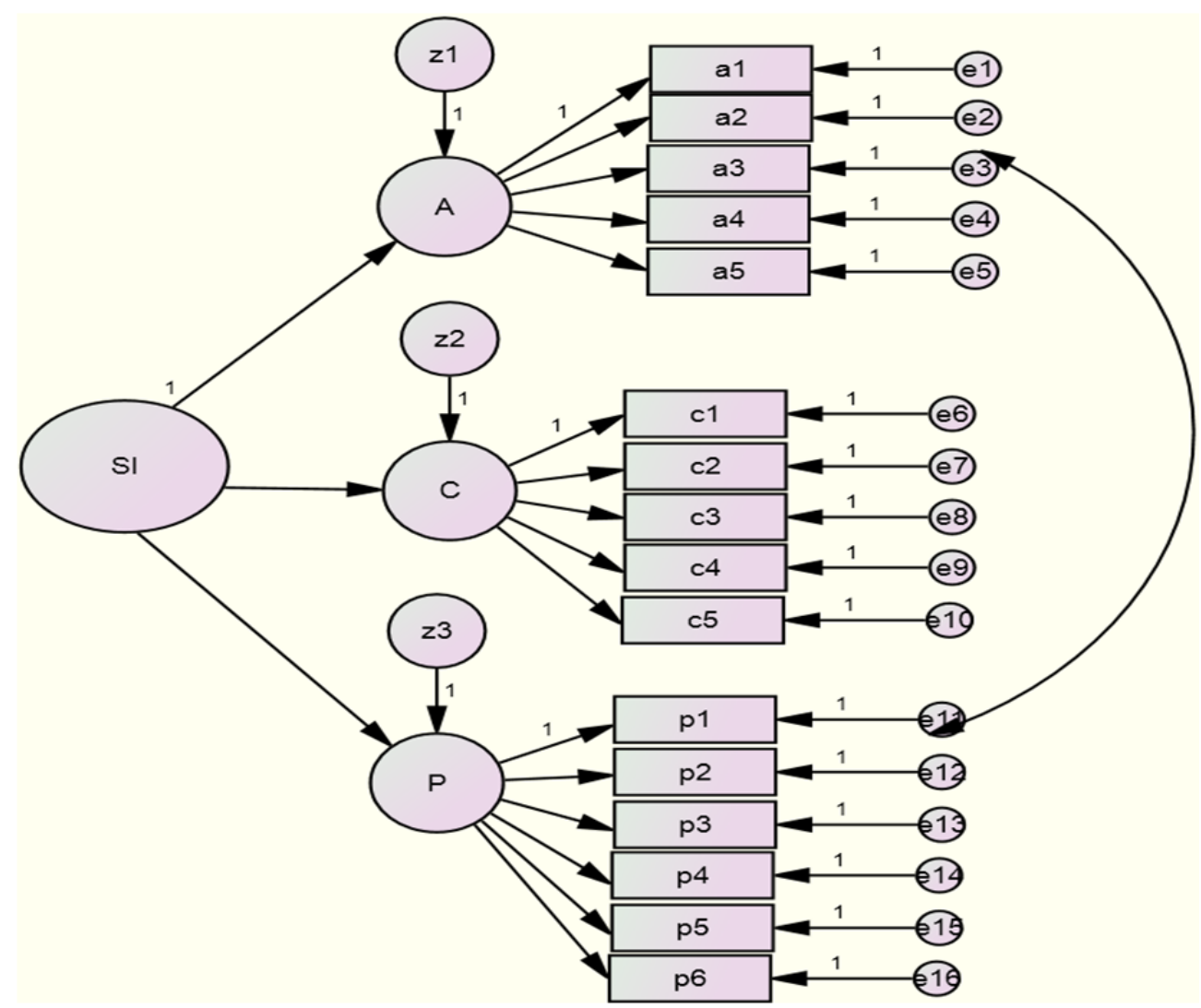

Figure 1. Path model with three first-order ability factors (analytical, creative, and practical)

Note. SI: Successful intelligence; A: Analytical; C: Creative; P: Practical.

Table 4. Fit indices for the estimated model

\begin{tabular}{cccccc}
\hline CMIN & DF & p & RMSEA & CFI & TLI \\
\hline 28.23 & 100 & 0.001 & 0.06 & 0.94 & 0.93 \\
\hline
\end{tabular}

Note. CMIN: Chi-Square value; DF: degrees of freedom; RMSEA: Root Mean Square Error of Approximation; CFI: Comparative Fit Indices; TLI: Tucker-Lewis Index.

As it is showed in table 4, the CFI, RMSEA, CIMN and TLI indexes are used as fit indices.

\section{Discussion}

In this article, we focused on confirmatory factor analysis of Aurora-a (according to Sternberg's theory of successful intelligence) on Iranian children. Since Aurora is a new instrument, multiple strands of evidence are needed to demonstrate its sound psychometric properties for gifted identification, and its potential as a monitoring tool to be used in gifted education (Mandelman, Barbot, Tan, \& Grigorenko, 2013). This instrument was adapted for the Iranian culture and was administered to 400 Iranian children. In order to adapt it to the Iranian culture some of the items were changed. Analyses including correlation, reliability and confirmatory factor analysis were conducted in order to gain a better understanding of the Aurora-a and the implications of Sternberg's model. The correlations between the Aurora-a total score and the analytical, creative and practical abilities were high $(0.91,0.94$ and 0.84 , respectively). The value of Cronbach's alpha was 0.92.

Mandelman et al. (2013) investigated Aurora's convergent and divergent validity using the Terra Nova, a conventional assessment of academic achievement. They then explore the overlap of these assessments with regard to whom they identify as gifted. Results in their research suggest Aurora's psychometric properties and ability to discriminate a more encompassing form of giftedness. Kornilov et al. (2012) believed that Aurora test can be employed in recognizing gifted children that are routinely missed by traditional methods. They study the relationship between Aurora scores and the assessments generally applied to identify gifted children in the United Kingdom schools. The results of their study showed that Aurora scores were related to students' 
achievement scores on the KS and MidYIS tests (Kornilov et al., 2012).

Aljughaiman \& Ayoub (2012) translated the Aurora into Arabic and standardized the Aurora in Saudi Arabia. They calculated the validity of Aurora test by confirmatory factor analysis that supported the construct validity of Aurora-a. The reliability coefficient of the Aurora-a-test was measured using Cronbach's alpha. These values were all statistically significant (Aljughaiman \& Ayoub, 2012).

The aim of Aurora-a is emphasizing need for identification instruments that are according to the real world demands. It seems that today's world, needs to talented people that are empowered not only to analyze and remember but also to apply and create (Kornilov et al., 2012).

The Aurora-a test is unique in the theory it employs, and its design, format and administration. It has a strong potential to fill a substantial gap in school practice by providing information on a child's cognitive ability that is accessible to and usable by educators in the classroom that can lead to tailored instructional interventions (Mandelman, Barbot, \& Grigorenko, 2015).

In conclusion, this study like above studies represents a step toward the identification and education of gifted. The Aurora-a is an assessment tool used to identify high ability in the areas of analytical, creative and practical abilities and is according to Sternberg's theory of successful intelligence. When these abilities are identified and nurtured, the most important form of human capital will be developed. Consequently, it is important to recognize children as gifted according to their various mental abilities and also to educate these abilities. This leads to the anticipation of the challenges in future labor markets which are capitalizing on creative and practical intellectual gifts, in addition to analytical abilities.

\section{Acknowledgements}

I gratefully acknowledge the help of the Aurora Battery Project Team (Aurora Team) in Child Study Center at Yale University especially Mei Tan. Without their help, this work would have never happened. I also like to thank of the students, mothers, fathers, teachers and school staff.

\section{References}

Aljughaiman, A. M., \& Ayoub, A. E. (2012). The effect of an enrichment program on developing analytical, creative and practical abilities of elementary gifted students. Journal for the Education of the Gifted, 35, 153-174. http://dx.doi.org/10.1177/0162353212440616

Chart, H., Grigorenko, E. L., \& Sternberg, R. J. (2008). Identification: The Aurora Battery. In J. A. Plucker, \& C. M. Callahan (Eds.), Critical issues and practices in gifted education, 345-365. Waco, TX: Prufrock Press.

Flanagan, D. P., \& Harrison, P. L. (2005). Contemporary intellectual assessment: Theories, tests, and issues (2nd Ed.). New York: Guilford Press.

Gardner, H. (1993). Multiple intelligences. New York: Basic Books.

Gardner, H. (1999). Intelligence reframed: Multiple intelligences for the 21st century. New York: Basic Books.

Kaufman, A. S., Lichtenberger, E. O., Fletcher-Janzen, E., \& Kaufman, N. L. (2005). Essentials of KABC-II Assessment. New York: Wiley.

Kornilov, S. A., Tan, M., Elliott, J. G., Sternberg, R. J., \& Grigorenko, E. L. (2012). Gifted identification with Aurora: Widening the spotlight. Journal of Psycho Educational Assessment, 30, 117-133. http://dx.doi.org/10.1177/0734282911428199

Mandelman, S. D., Barbot, B., \& Grigorenko, E. L. (2015). Predicting academic performance and trajectories from a measure of successful intelligence. In Press, Learning and Individual Differences. http://dx.doi.org/10.1016/j.lindif.2015.02.003

Mandelman, S. D., Barbot, B., Tan, M., \& Grigorenko, E. L. (2013). Addressing the quiet crisis: Gifted identification with Aurora. Educational \& Child Psychology, 30, 101-109.

Mandelman, S. D., Tan, M., Kornilov, S. A., Sternberg, R. J., \& Grigorenko, E. L. (2010). The metacognitive component of academic self-concept: The development of a triarchic self-scale. Journal of Cognitive Education \& Psychology, 9, 73-86. http://dx.doi.org/10.1891/1945-8959.9.1.73

Mather, N., Wendling, B. J., \& Woodcock, R. W. (2001). Essentials of WJ III Tests of Achievement Assessment. New York: Wiley.

Renzulli, J. S. (2005). The three-ring conception of giftedness. In R. J. Sternberg, \& J. E. Davidson (Eds.), Conceptions of Giftedness, 246-279. New York: Cambridge University Press. 
http://dx.doi.org/10.1017/CBO9780511610455.015

Roid, G. H., \& Barram, R. A. (2004). Essentials of Stanford-Binet Intelligence Scales (SB5) Assessment. New York: Wiley.

Sternberg, R. J. (1985). Beyond IQ: A triarchic theory of human intelligence. New York: Cambridge University Press.

Sternberg, R. J. (1997). A waste of talent. Education Week, 17, 56.

Sternberg, R. J. (1999). The theory of successful intelligence. Review of General Psychology, 3, 292-316. http://dx.doi.org/10.1037/1089-2680.3.4.292

Sternberg, R. J. (2002). Raising the achievement of all students: Teaching for successful intelligence. Educational Psychology Review, 14, 383-393. http://dx.doi.org/10.1023/A:1020601027773

Sternberg, R. J. (2005). The theory of successful intelligence. Inter-American Journal of Psychology, 39, 189-202.

Sternberg, R. J. (2010). Assessment of gifted students for identification purposes: New techniques for a new $\begin{array}{llll}\text { millennium. Learning and Individual Differences, } & \text { 20, 327-336. }\end{array}$ http://dx.doi.org/10.1016/j.lindif.2009.08.003

Sternberg, R. J. (2015). Successful intelligence: A model for testing intelligence beyond IQ tests. European Journal of Education and Psychology, 8, 76-84. http://dx.doi.org/10.1016/j.ejeps.2015.09.004

Sternberg, R. J., \& Grigorenko, E. L. (2004). Successful intelligence in the classroom. Theory into Practice, 43, 274-280. http://dx.doi.org/10.1207/s15430421tip4304_5

Tan, M., Aljughaiman, A. M., Elliott, J. G., Kornilov, S. A., Ferrando-Prieto, M., Bolden, D. S. ... Grigorenko, E. L. (2009). Considering language, culture, and cognitive abilities: The international translation and adaptation of the Aurora Assessment Battery. In E. L. Grigorenko (Ed.), Multicultural Psychoeducational Assessment, 443-468. New York, NY: Springer.

\section{Copyrights}

Copyright for this article is retained by the author(s), with first publication rights granted to the journal.

This is an open-access article distributed under the terms and conditions of the Creative Commons Attribution license (http://creativecommons.org/licenses/by/3.0/). 